Available online on 15.06 .2020 at http://jddtonline.info
Open Access to Pharmaceutical and Medical Research
(c) 2011-18, publisher and licensee JDDT, This is an Open Access article which permits
unrestricted non-commercial use, provided the original work is properly cited

Open $\odot$ Access

Review Article

\title{
A Novel Coronavirus (nCOV- 2019): A Pandemic Severe Respiratory Tract Infections by SARS COV-2 in Human
}

\author{
Vikram Jadhao1, Roshan Bodhe ${ }^{1 *}$, Hitendra Mahajan' ${ }^{1}$, Vikram Jadhav ${ }^{2}$, Kishor Patil ${ }^{3}$, Nupur Baheti ${ }^{4}$, Neha Kale ${ }^{4}$ \\ ${ }^{1}$ Department of Pharmaceutics, R.C. Patel Institute of Pharmaceutical Education \& Research, Shirpur - 425405, India \\ ${ }^{2}$ Central Drug Standard Control Organization Nhava Sheva, Navi Mumbai -400707, India \\ 3 Department of Pharmaceutical Science, London Metropolitan University, Hollyway Road London -166-220, United Kingdom \\ ${ }^{4}$ University Department of Biotechnology, SGB University Amravati, 444602, India
}

\begin{abstract}
Novel Coronavirus Disease 2019 (nCOV 2019) or Coronavirus is one which is associate communicable disease amongst variety of viruses that causes cold, fever, difficulty in breathing and ultimately death. The viruses cause metabolism infections, together with the mundane cold, that square measure usually delicate, although a lot of occasional forms like respiratory illness caused by SARS-CoV-2, the illness is that the reason for the 2019-20 coronavirus irruption. It's primarily unfolded between individuals by diminutive droplets from infected people once they breathe or cough. Individuals could have few symptoms or develop febrility, cough, and shortness of breath. Whereas Feb 2020 , different countries together with European country Asian Countries enclosed within the list. Antiviral drugs being tested embrace antimalarial drug, the ribonucleic acid enzyme substance remdesivir, and triazavirin, Umifenovir (Arbidol) and darunavir were planned. Remdesivir an d antimalarial drug effectively inhibit the coronavirus in vitro. Favilavir approved as experimental corona virus drug. The objective of this review article to provide basic knowledge \& preliminary opinion and to provide an advice which can be proved as the best mantra for defeating nCOV. Thus this review aims to throw light to the new and exciting areas of Virology, Replication cycle of corona virus , sign \& symptoms and diagnosis, Spreading of corona virus, Structural biology of corona virus, the ways of treatment with alternative medicines other than antiviral drugs, and prevention in its early stage of COVID-19, and also Current Research on Corona.
\end{abstract}

Keywords: Coronavirus, 2019-nCOV2, 2019-20 coronavirus irruption, SARS, WHO, Public Health Emergency of International Concern (PHEIC), replication of corona virus.

Article Info: Received 26 March 2020; Review Completed 17 May 2020; Accepted 22 May 2020; Available online 15 June 2020

\section{Cite this article as:}

Jadhao V, Bodhe R, Mahajan H, Jadhav V, Patil K, Baheti N, Kale N, A Novel Coronavirus (nCOV- 2019): A Pandemic Severe Respiratory Tract Infections by SARS COV-2 in Human, Journal of Drug Delivery and Therapeutics. 2020; 10(3-s):271-279 http://dx.doi.org/10.22270/jddt.v10i3-s.4120

*Address for Correspondence:

Roshan Gomaji Bodhe, Department of Pharmaceutics, RC Patel Institute of Pharmaceutical Education \& Research, Near Karwand, Naka Shirpur425405, Maharashtra, India

\section{Introduction}

A coronavirus is one amongst variety of viruses that cause diseases in mammals and birds. In humans, the viruses cause metabolism infections, together with the mundane cold, that square measure usually delicate, although a lot of occasional forms like respiratory illness, MERS and COVID-19 may be fatal. Symptoms vary in different species: in chickens, they cause associate higher respiratory illness, whereas in cows and pig's coronaviruses cause symptom. There are not any vaccines or antiviral medicine to obviate or treat human coronavirus infections. Coronaviruses comprise the taxonomic group Orthocoronavirinae within the family corona viridae within the order Nidovirales [1, 2]. They are engulfed viruses with a positive-sense single-stranded RNA genome and a nucleo capsid of spiral symmetry. The ordinary size of coronaviruses ranges from more or less twenty six to thirty two kilo bases, the foremost vastly large among kenned ribonucleic acid viruses. The designation coronavirus springs from the Latin corona, designating "crown" or "halo", that refers to the characteristic look of the virus particles (virions): they need a fringe love a crown or of a star corona. . This morphology is engendered by the infective agent spike $(S)$ peplomers, those square measure proteins on the surface of the virus that confirm host response. Proteins that contribute to the general structure of all coronaviruses square measure the spike (S), envelope $(\mathrm{E})$, membrane $(\mathrm{M})$, and nucleocapsid $(\mathrm{N})$ within the categorical case of the respiratory illness coronavirus, an outlined receptor-binding domain on $\mathrm{S}$ mediates the annexation of the 
virus to its cellular receptor, angiotensin-converting catalyst two (ACE2) [3,4,5]. Some coronaviruses (concretely the members of Betacoronavirus subgroup A) nonetheless have a shorter spike-like macromolecule known as hemagglutinin esterase (HE). Coronaviruses were discovered within the Nineteen Sixties. The earliest ones discovered were infectious respiratory illness virus in chickens and 2 viruses from the nasal cavities of human patients with the mundane cold that were afterwards denominated human coronavirus 229E and human coronavirus OC43. Different members of this family have since been known, together with SARS-CoV in 2003, HCoV NL63 in 2004, HKU1 in 2005, MERS-CoV in 2012, and SARS-CoV-2 (formerly kenned as 2019-nCoV) in 2019; most of those are concerned in solemn tract infections. The SARS-CoV-2 shown in fig 1.

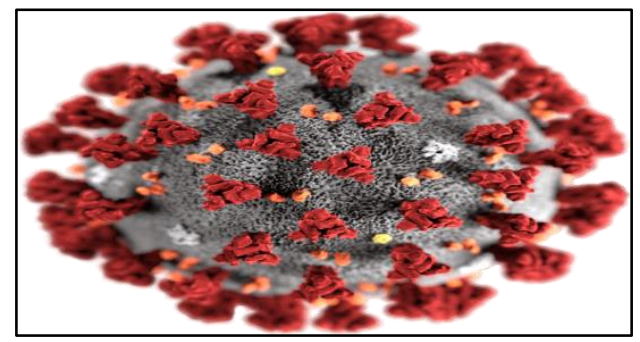

Fig 1: SARS-CoV-2 particle

\section{Replication}

When cell ingression, the virus particle is uncoated and its ordination enters the cell living substance. The coronavirus ribonucleic acid ordination features a cap and a $3^{\prime}$ polyadenylated tail that sanctions the ribonucleic acid to annex to ribosomes for translation. Coronavirus ordinations in addition encodes a macromolecule known as a replicase that sanctions the infective agent genome to be transcribed into early ribonucleic acid copies utilizing the host cell's machinery. The replicase is that the initial macromolecule to be made; once the factor coding the replicase is translated, translation is ceased by a surcease sequence. This can be kenned as a nested transcript. Once the template RNA transcript solely encodes one factor, its monocistronic. A coronavirus non-structural macromolecule provides further fidelity to replication as a result of it confers a proofreading operate, that is empty of in ribonucleic acid-dependent RNA enzyme enzymes alone. The ordination is replicated and an extended poly-protein consists, wherever all of the proteins square measure affixed. Corona viruses have a nonstructural macromolecule a proteinase that is ready to cleave the poly-protein. This method may be a kind of genetic economy sanctionative the virus to write the best variety of genes in a very minuscule variety of nucleotides. Rigorous acute metabolism syndrome coronavirus two (SARS-CoV-2) [ 6,7 8,9] Erst kenned because the 2019 novel coronavirus (2019-nCoV) [10,11] may be a positive-sense fibre ribonucleic acid virus.[12,13,14] it's contagious among humans and is that the reason for coronavirus illness 2019 (COVID-19).[15, 16] there's no vaccinum. SARS-CoV-2 has vigorous genetic same attribute to kenned bat corona viruses, creating a animal disease origin in haywire possible albeit associate intermediate reservoir like a placental mammal is believed to be concerned.[ 17, 18, 19, 20,21] From a categorisation perspective SARS-CoV-2 is relegated as a Strain of the species rigorous acute metabolism syndrome-cognate coronavirus. SARS-CoV-2 is that the reason for the perpetual 2019-20 coronavirus irruption, a Public Health Emergency of International Concern that originated in metropolis, China. Attributable to this association the virus is usually named informally among different sobriquets because the "Wuhan coronavirus Replication cycle of coronavirus shown in fig $2[22,23,24]$.

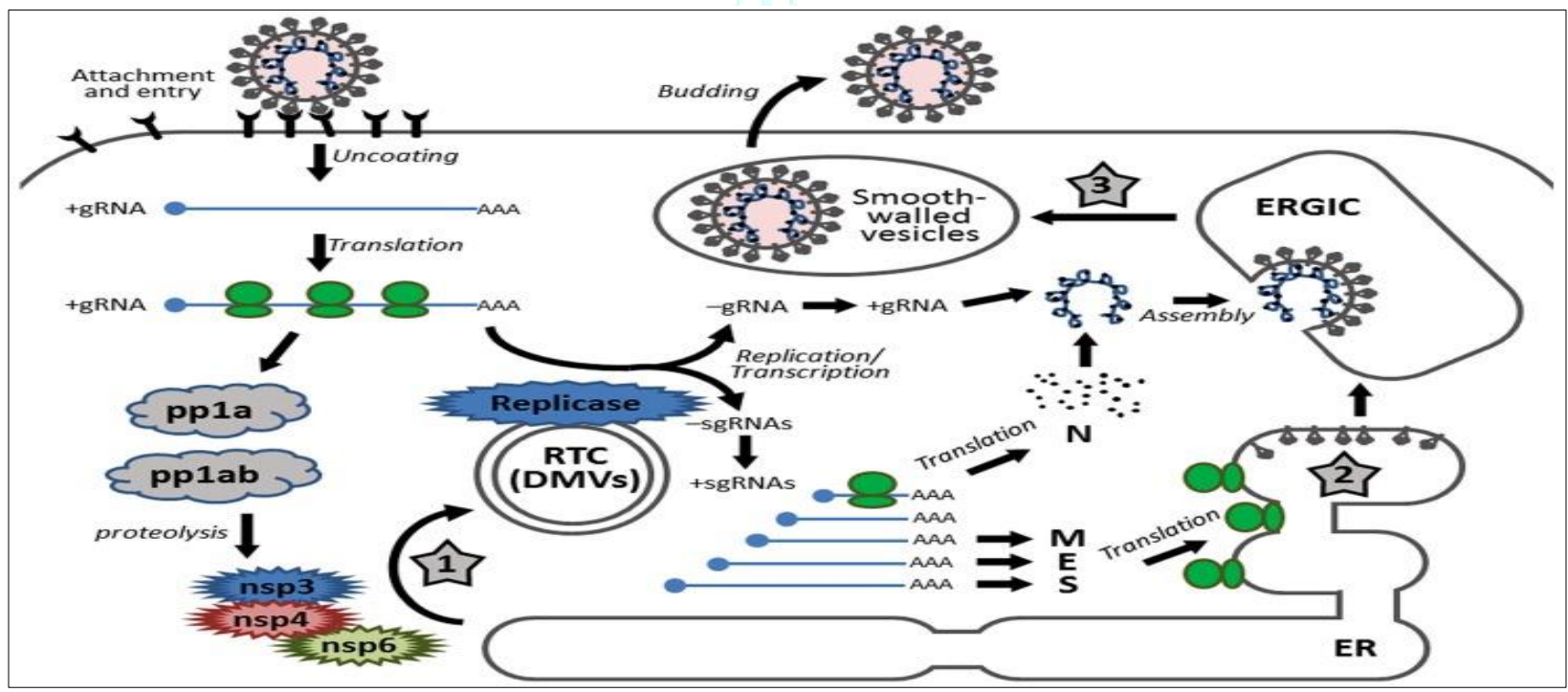

Figure: 2.Schematic diagram showing the replication cycle of coronavirus

Infection starts with receptor binding and entry by membrane fusion. After uncoating, the genomic RNA is used as a template to synthesize progeny genomes and a nested set of subgenomic RNAs. The replication transcription centers are closely associated with DMVs, which are proposed to be adopted from the modified ER, possibly by the combined activities of non-structural proteins nsp3, nsp4, and nsp6. The S, E, and M proteins are synthesized and anchored on the ER, whereas the $\mathrm{N}$ protein is translated in the cytosol. Assembly takes place in the ERGIC and mature virions are released via smooth-walled vesicles by exocytosis. The three stages that presumably induce ER stress are highlighted with numbered star signs, namely: (1) formation of DMVs, (2) massive production and modification of structural proteins, and (3) depletion of ER membrane during budding.

\section{9-20 coronavirus outbreak:}

The 2019-20 coronavirus irruption is associate perpetual epidemic of coronavirus illness 2019 (COVID-19) caused by SARS-CoV-2, that commenced in Dec 2019. It absolutely was initial known in metropolis, capital of Hubei province, China, 
when forty one individuals bestowed with respiratory illness of no clear cause. It will unfold between individuals, with the time from exposure to onset of symptoms typically between two and a time period [25].Symptoms could embrace febrility, cough, and shortness of breath [26] .Complications could embrace respiratory illness and acute metabolism distress syndrome. There's no vaccine or categorical antiviral treatment with efforts usually to management symptoms and support functioning [27] .Hand laundry is suggested to avert unfold of the illness [28].Anyone UN agency is suspected of carrying the virus is suggested to watch their health for a time period, wear a mask, and look for medical recommendation by line of work a medico instead of directly visiting a clinic [29]. The epidemic is presently the third most vastly large of the twenty first century [30]. As of nineteen Feb 2020, 75,727 cases are substantiated, together with altogether provinces of China and over XXIV different countries [31] of those, 11,795 cases square measure earnest [32].In China, the mundane increase of early cases peaked between twenty three and twenty seven Gregorian calendar month [33] specialists have notionally theorized that a lot of individuals could also be infected than officers have verified [34,35].The illness has killed two,128 people, together with eight outside Communist China.[36] This surpasses the 774 deaths from the 2003 respiratory illness irruption.[36]. The irruption has been declared a Public Health Emergency of International Concern (PHEIC) by the globe Health Organization (WHO) $[37,38]$. Health ascendant entities are operating to contain the unfold of the illness since its revelation [39, 40,41] .China has introduced jaunt restrictions, quarantines, and alfresco restrictions requiring families to remain at home-affecting over a hundred and seventy million individuals [41]. A variety of nations have issued caveats against jaunt to metropolis, Hubei, or China typically [42, 43].Airports and train stations have enforced temperature checks, health declarations, and knowledge accumulation in a shot to spot carriers of the virus [44]. Misinformation has unfolded concerning the coronavirus, primarily on-line, that the UN agency represented as associate "infodemic" on two Feb 2020. The epidemic has light-emitting diode to more consequences on the far side quarantine measures and its impact on health, together with considerations over potential economic instability and repeal of many events expected to be attended by individuals move from areas with high risk of contagion[45].Political consequences have enclosed variety of native bellwethers of the Chinese political party being laidoff because of their replication to the irruption [46] .Reports of social phobia and racism against individuals of Chinese and East Asian descent have arisen as a results of the irruption, with concern and quarrelsomeness occurring in many countries shown in fig $3[47,48,49,50,51]$.

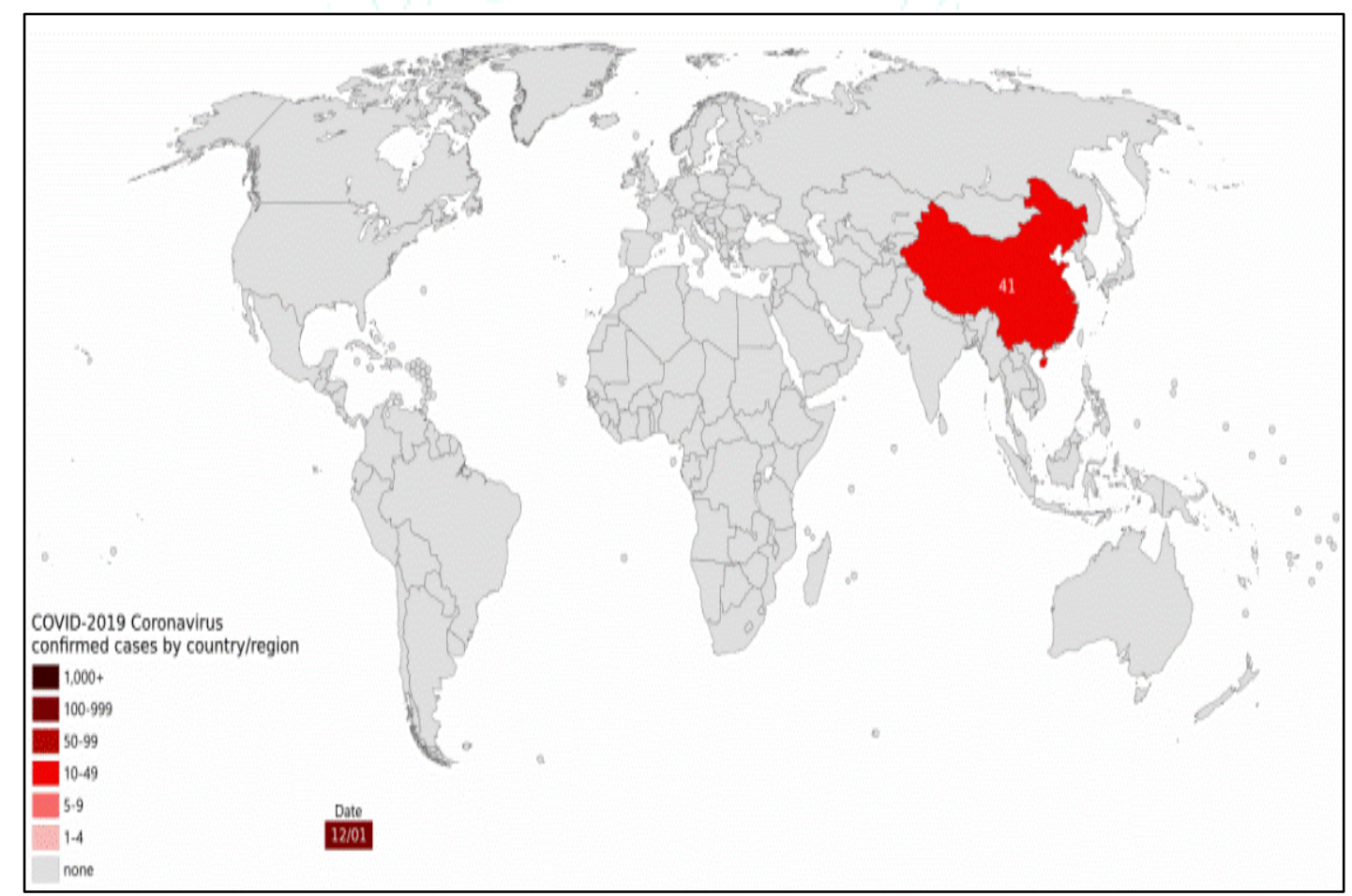

Figure 3: The map of confirmed COVID-19 cases from twelve Gregorian calendar month 2020 to 3 rd March 2020.

\section{SARS Infection- Coronavirus illness 2019}

Coronavirus illness 2019 (COVID-19) rest kenned as 2019$\mathrm{nCoV}$ acute respiratory disease, is associate communicable disease caused by SARS-CoV-2, a plague proximately cognate to the respiratory illness virus:[52, 53,54$]$ the illness is that the reason for the 2019-20 coronavirus irruption.[55,56]it is primarily unfold between individuals via metabolism droplets from infected people once they cough or sneeze [57].Time from exposure to onset of symptoms is usually between two and a time period [58] unfold may be suppressed by hand-washing and different hygiene measures [59].The illness could at first gift with few or no symptoms, or could be converted into febrility, coughing, shortness of breath, pain within the muscles and lassitude [60] more development could embrace respiratory illness and acute metabolism distress syndrome. There aren't any vaccines not categorical antiviral treatments approved for this illness, with efforts usually confined to management of symptoms and auxiliary measures [61]. Cases were at first known in metropolis, capital of Hubei province in China in Dec 2019. Afterwards, infections are according round the world. Cases according outside China have preponderantly been in those who have recently travelled to Communist China, but a number of cases of native transmission have in addition occurred. over two,000 deaths are according in Communist China, and eight deaths in different elements of the globe [62].The World Health Organization (WHO) and U.S. 
Centers for illness management (CDC) suggest that persons UN agency suspect that they're carrying the virus wear a surgical mask and look for medical recommendation by line of work a medico instead of directly visiting a clinic in the flesh [63,64].The UN agency has declared the 2019-20 coronavirus irruption to be a Public Health Emergency of International Concern (PHEIC) [65].As of nineteen Feb 2020, solely Communist China is listed as a region with kenned perpetual community unfold of the illness [66].

\section{Backgrounds of disease}

On Gregorian calendar month twelve, 2003, scientists acting at the Michael Smith ordination Sciences Centre in Vancouver culminated mapping the genetic sequence of a coronavirus believed to be connected to respiratory illness. The team was light-emitting diode by Dr. Marco Marra and worked together with a people Columbia Centre for illness management and therefore the National biology Laboratory in Winnipeg, Manitoba, utilizing samples from infected patients in Toronto. The map, hailed by the UN agency as a of import leap forward in fighting respiratory illness, is shared with scientists ecumenical via the GSC web site. Dr. Donald Low of Mount Sinai Hospital in Toronto represented the revelation as having been created with "unprecedented speed". The sequence of the respiratory illness coronavirus has since been documented by different freelance teams. In unpunctual could 2003, studies from samples of untamed animals oversubscribed as aliment within the native market in Guangdong province, China, found a strain of respiratory illness coronavirus may be isolated from cloaked palm civets (Paguma sp.), however the animals failed to forever show clinical signs. The preliminary conclusion was the respiratory illness virus crossed the xenographic barrier from palm cat to humans, and over ten, 000 cloaked palm civets were killed in province. The virus was in addition later found in raccoon canines (Nyctereuteus sp.), ferret badgers (Melogale spp.), an nd domestic felines. In 2005, 2 studies known variety of SARS-like corona viruses in Chinese haywire [67] organic process analysis of those viruses selected a high chance that respiratory illness coronavirus originated in haywire and unfold to humans either directly or through animals control in Chinese markets. The haywire failed to show any visible denotements of illness, however square measure the possible natural reservoirs of SARS-like corona viruses. In unpunctual 2006, scientists from the Chinese Centre for illness management and preclusion of Hong Kong University and therefore the Canton Centre for illness management and preclusion established a genetic link between the respiratory illness coronavirus showing in civets and humans, Verificatory claims that the illness had jumped across species [68] .Corona viruses were known within the mid-1960s and square measure kenned to infect humans and a spread of animals (including birds and mammals). Since 2002, 2 corona viruses infecting animals have evolved and caused outbreaks in humans: SARS-CoV (2002, Betacoronavirus, taxonomic category Sarbecovirus), and MERS-CoV (2012, Betacoronavirus, taxonomic category Merbecovirus).

In 2002-2003, SARS-CoV affected eight 096 individuals, inflicting astringent pulmonic infections and 774 deaths (case fatality ratio: $10 \%$ ). haywire were the possible origin of the virus, that unfold more to range palm civets, Chinese ferret badgers and raccoon canines oversubscribed for victuals at the wet markets of Guangdong province, China. MERS-CoV was known in 2012 in Asian nation and since then the bulk of human cases are according from the Arabian Peninsula. Human-to-human- transmission, unconditionally in care settings, has been the most route of transmission. However, Camelusdromedarius camels square measure overriding animal reservoirs of the virus. The case fatality magnitude relation of MERS-CoV infections is calculable at thirty fifth. In Dec 2019, a unique astringent acute metabolism syndrome coronavirus (SARS-CoV-2) was initial isolated from 3 patients with respiratory illness, connected to the cluster of acute respiratory disease cases from metropolis, China. Genetic analysis disclosed that SARS-CoV2 is proximately cognate to SARS-CoV and genetically clusters inside the genus Betacoronavirus, composing a definite biological group in lineage $B$ of the taxonomic category Sarbecovirus along with 2 bat-derived incremented transmissions on the far side SARS-CoV-like strains [69, 70]. The inchoation of the virus isn't pellucid however. A recent study documented that vasoconstrictive changing catalyst two (ACE 2), a membrane exopeptidase, is that the receptor utilised by SARS-CoV-2 for ingress into the human cells, love SARS-CoV[71]. The virus was at first isolated in mustang alveolar irrigation fluid samples, and infective agent ribonucleic acid has thenceforth been detected in bodily cavity and throat swabs further as in bodily fluid [72, 73] blood, body part swabs, saliva, piss and stool [75, 76] Information on the medical specialty and clinical characteristics of the infection caused by SARS-CoV-2 is accumulating. Within the initial printed studies utilizing patient information from Chinese hospitals, the foremost mundane clinical symptom in hospitalised patients was febrility, followed by cough, dyspnoea and pain, one amongst the studies nonetheless according fatigue as an awfully mundane symptom. Symptom and regurgitating, however, were according as unorthodox symptoms more or less third of the patients developed dyspnoea when 5 days (interquartile vary (IQR) 1-10) from the onset of symptoms, and 23-26\% needed admission to the medical aid unit (ICU) when a median of ten days (IQR 6-12). Invasive mechanical ventilation was according for forty seventh of the intensive care unit patients in another study; extracorporeal membrane activity (ECMO) was according for seven patients within the 2 studies with over two hundred patients. Adscititiously, Xraying imaging and $\mathrm{x}$-ray of the chest known seventy fifth of the cases having bilateral abnormalities, whereas another study according all patients exhibiting bilateral involution in $\mathrm{X}$-raying.

\section{Virology}

\section{Infection}

Human-to-human transmission of the virus has been attested[77] and happens primarily via metabolism droplets from coughs and sneezes inside a variety of concerning vi feet $(1.8 \mathrm{~m})$ [78][79] infective agent ribonucleic acid has in addition been found in stool samples from infected patients [80] it's doable that the virus may be infectious even throughout the period, however this has not been well-tried, [81] and therefore the UN agency verbally expressed on one Feb 2020 that "transmission from well cases is probably going not a serious driver of transmission" at now.

\section{Reservoir}

Animals oversubscribed for victuals were pristinely suspected to be the reservoir or negotiate hosts of SARS$\mathrm{CoV}-2$ as a result of several of the primary people found to be infected by the virus were employees at the Huainan food Market. A market commerce live animals for victuals was nonetheless incriminated within the respiratory illness irruption in 2003; such markets square measure thought of to be incubators for novel pathogens. The irruption has prompted a poster interim require on the trade and consumption of untamed animals in China. However, some researchers have prompt that the Huainan food Market might not be the pristine supply of infective agent 
transmission to humans. Research into the origin of the 2003 respiratory illness irruption has resulted within the revelation of the many SARS-like bat corona viruses, most originating within the Rhinolophus genus of horseshoe haywire. 2 infective agent macromolecule sequences from Rhinolophussinicus printed in 2015 and 2017 show a similitude of eightieth to SARS-CoV-2. A third infective agent macromolecule sequence from Rhinolophusaffinis, "RaTG13" accumulated in state, features a ninety six similitude to SARS-CoV-2. For comparison, this amplitude of variation among viruses is kindred to the magnitude of mutation visually examined over 10 years within the H3N2 human contagious disease virus strain. Researchers from Canton claim to own found a "99\% identical" infective agent macromolecule sequence in a very placental mammal sample. As of twelve Feb 2020, the sequence remains inaccessible, and every one data emanates from university promulgation. Pangolins square measure bulwarked underneath Chinese law, however cookery and commerce of pangolins for ancient medication remains rife. A metagenomics study printed in 2019 foretime disclosed that SARS-CoV was the foremost cosmopolitan coronavirus among a sample of Malayan pangolins. Microbiologists and geneticists in American state have severally found proof of recombination in corona viruses suggesting placental mammal inchoation of SARS-CoV-2; they acknowledged remaining unknown factors whereas urging perpetuated examination of different mammals.

\section{Phylogenetic and taxonomy}

SARS-CoV-2 belongs to the broad family of viruses kenned as corona viruses. It's a positive-sense fibre ribonucleic acid (+ssRNA) virus. Different corona viruses square measure capable of inflicting sicknesses starting from the rife cold to a lot of rigorous diseases like geographic region metabolism syndrome (MERS). it's the seventh kenned coronavirus to infect individuals, after 229E, NL63, OC43, HKU1, MERS-CoV, and therefore the pristine SARS-CoV[82].Like the respiratory illness-cognate coronavirus strain involved within the 2003 SARS irruption, SARS-CoV-2 may be a member of the taxonomic category Sarbecovirus (Beta-CoV lineage B).Its ribonucleic acid sequence is more or less thirty, 000 bases long. With associate ample variety of sequenced genomes, it's doable to reconstruct an organic process tree of the mutation history of a family of viruses. By twelve Gregorian calendar month 2020, 5 genomes of SARS-CoV-2 had been isolated from metropolis and according by the Chinese canter for illness management and Aversion (CCDC) and different institutions; the amount of genomes incremented to eighty one by eleven Feb 2020. A phylogenic analysis of the samples shows they're "highly cognate with at the most seven mutations relative to a rife antecedent", implicatively insinuating that the primary human infection occurred in Nov or Dec 2019. On eleven Feb 2020, ICTV publicized that per subsisting rules that work out hierarchical relationships among corona viruses on the substrate of 5 preserved sequences of nucleic acids, the distinctions between what was then known as 2019-nCoV and therefore the virus strain from the 2003 respiratory illness irruption were inadequate to form it a separate infective agent species. Ergo, they knew 2019-nCoV as a strain of astringent acute metabolism syndrome-cognate coronavirus.

\section{Structural biology}

Protein modelling experiments on the spike (S) macromolecule of the virus recommend that it's ample affinity to the vasoconstrictive changing catalyst two (ACE2) receptors of human cells to utilize them as a mechanism of cell ingression. On twenty two Gregorian calendar month 2020, a gaggle in China operating with the total virus ordination and a gaggle within the united States utilizing reverse genetic science strategies severally and through an experiment incontestible that ACE2 might act because the receptor for SARS-CoV-2.Studies have shown that respiratory illness-CoV-2 features a higher affinity to human ACE2 than the pristine SARS virus strain. To look for potential proteinase inhibitors, the infective agent $3 \mathrm{C}$-like proteaseM (pro) from the ORF1a polyprotein has in addition been modelled for drug tying up experiments. Innophore has engendered 2 machine models predicated on respiratory illness proteinase, and therefore the Chinese Academy of Sciences has engendered associate unpublished experimental structure of a recombinant 2019-nCoV proteinase. In integration, researchers have modelled the structures of all mature peptides within the SARS-CoV-2 ordination utilizing I-TASSER and Swiss-model shown in fig 4.

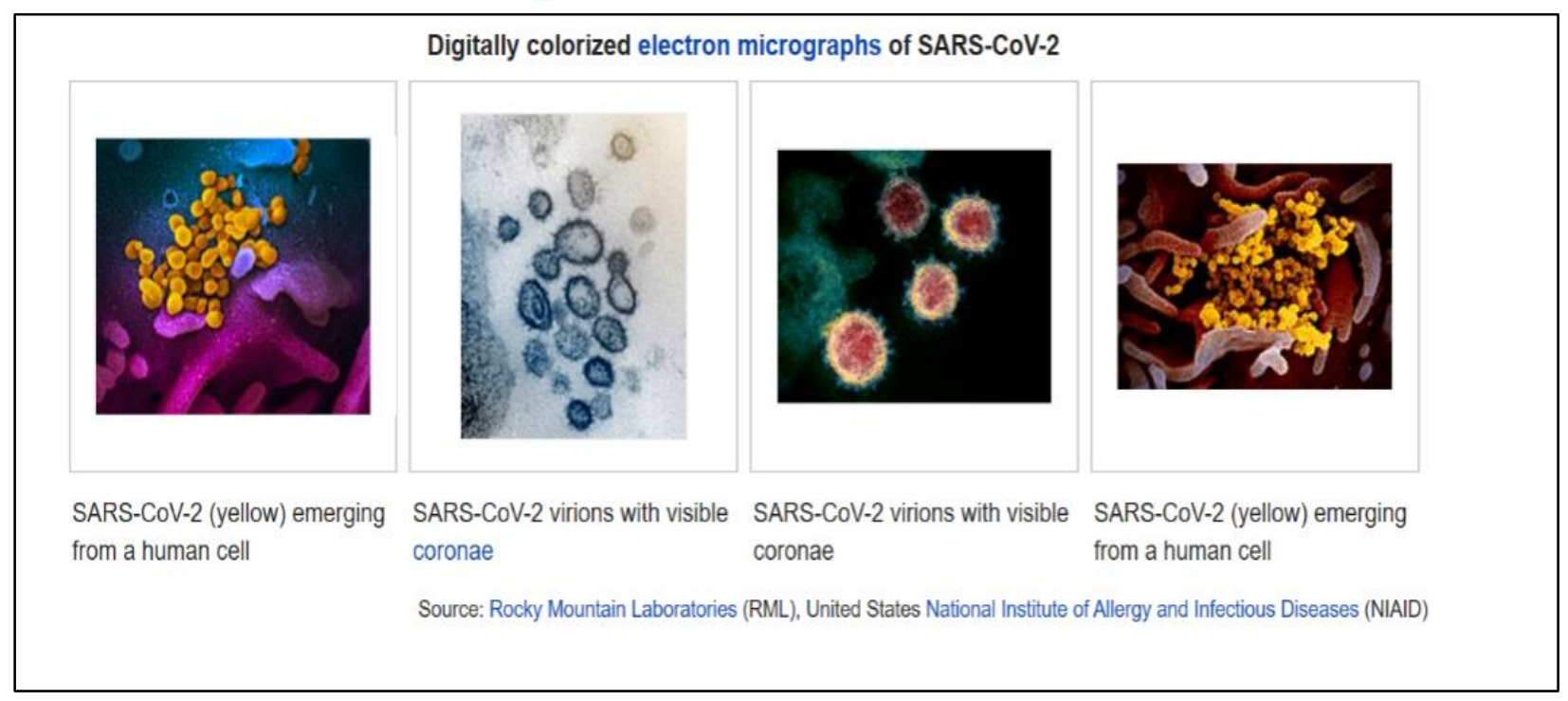

Figure 4: Digitally colorized negatron micrographs of SARS-CoV-2. 


\section{Signs and symptoms}

Those infected could either be well or develop symptoms, together with febrility, cough or shortness of breath. Diarrhoea or higher metabolism symptoms (e.g. sneezing, liquid nasal individual, and sore throat) square measure less frequent shown in fig 5[83].Cases will accomplish respiratory illness, multi-organ failure, and death. The length of the period is calculable to be between 2 and 10 days by the globe Health Organization and between 2 and a time period by the Cumulated States Centers for illness management and preclusion (CDC). A study had found elegant cases wherever the period was as long as twenty four days.

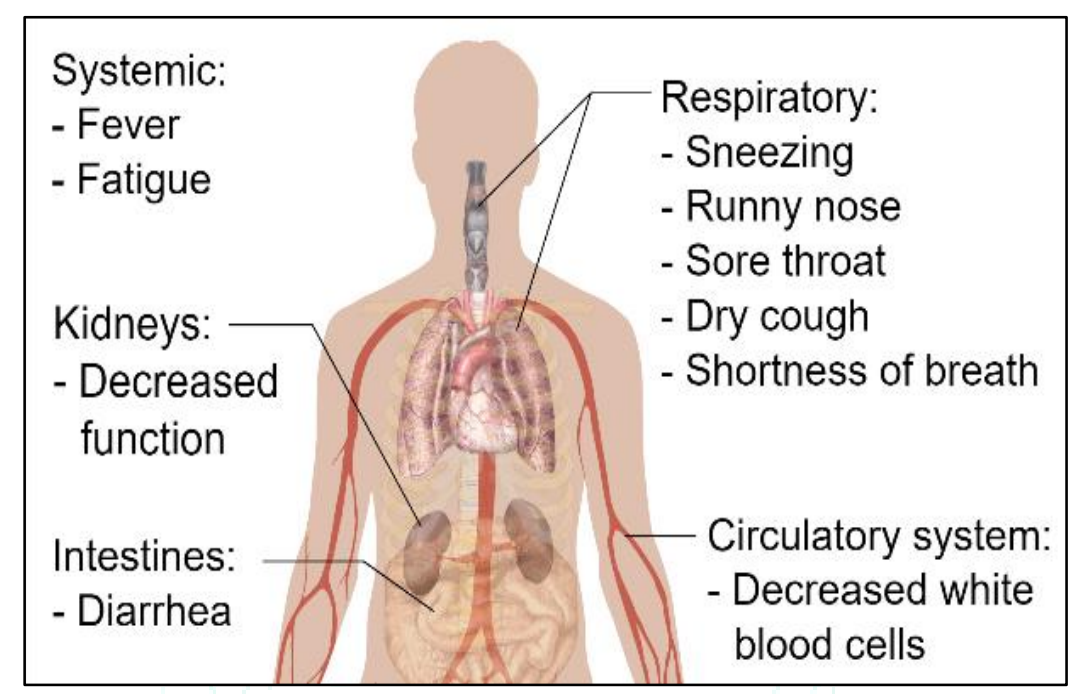

Figure: 5 - Sign \& Symptoms of corona virus.

\section{Causes}

The illness is caused by the virus rigorous acute metabolism syndrome coronavirus two (SARS-CoV-2), previously named because the 2019 novel coronavirus (2019-nCoV) [84].The virus is believed to own associate animal inchoation.

It is primarily unfold between individuals via metabolism droplets from the coughs and sneezes. officers in Shanghai documented many transmission modes, together with transmission mechanism, contact transmission and aerosol transmission, the latter 2 involving transmission once somebody physically contacts a surface contaminated with tainted metabolism droplets and inhalation of air contaminated with tainted metabolism droplets [85] An medical specialty study of the primary seventy two,314 cases prompt that there could are a "perpetual mundane source" of the irruption in Dec 2019, which might implicatively insinuate that many animal to human animal disease events occurred at the Huainan food Wholesale Market. Per this theory, the first supply of infection became human-to-human transmission in early Gregorian calendar month 2020 [86].

\section{Diagnosis}

The UN agency has printed many testing protocols for the illness. Testing uses real time reverse transcriptionpolymerase chain reaction (rRT-PCR) [87, 88].The take a look at may be done on metabolism or blood samples. Results square measure typically accessible inside a number of hours to days. Chinese scientists were ready to isolate a strain of the coronavirus and publish the genetic sequence so laboratories across the globe might severally develop PCR tests to find infection by the virus. Diagnostic tips relinquished by Zhongnan Hospital of metropolis University prompt strategies for detection infections predicated upon clinical options and medical specialty peril. These concerned distinctive patients UN agency had a minimum of 2 of the subsequent symptoms in integration to a history of jaunt to metropolis or contact with different infected patients: febrility, imaging options of respiratory illness, mundane or truncated white somatic cell count, or truncated white corpuscle count [87 88,89].

\section{Prevention}

- $\quad$ No vaccinum presently subsists against SARS-CoV-2.

- Interference is fixated on sensible hygiene. Individual's square measure suggested to scrub their hands with soap and dihydrogen oxide often; and to utilize hand sanitizer gel if soap and dihydrogen oxide don't seem to be accessible.

- Individual's square measure nonetheless suggested to not physically contact their ocular perceivers, nasal discerner or mouth if their hands don't seem to be immaculate.

- $\quad$ individuals square measure in addition suggested to hide their mouth or nasal individual with a tissue or sleeve once they cough or sneeze, and to get rid of utilised tissues directly.

- The Ministry of Health in Singapore lists many precautions underneath its health consultive, nonetheless advising individuals to not victual raw or undercooked meats; to remain away from jammed places and evade shut contact with those who square measure sick (something kenned as gregarious distancing). It's suggested against all non-essential jaunts to Communist China.

- Those who could also be infected square measure suggested to hunt medical attention promptly, line of work ahead afore visiting a care provider; and to remain reception, evading shut contact with others, together with avoid sharing personal home items.

- $\quad$ The employment of masks by salubrious members of the general public isn't counselled outside of China. However, people who square measure unwell square measure bold to wear a mask. 


\section{Current Research}

\section{Vaccine}

Many organizations square measure utilizing printed genomes to develop doable vaccines against SARS-CoV-2. Bodies developing vaccines embrace the Chinese Centre for illness management and Aversion] [90] the University of Hong Kong, and Hospital. 3 vaccinum comes square measure being fortified by the Coalition for Epidemic preparation Innovations (CEPI), together with comes by the biotechnology corporations Modern and Invivo prescription drugs and another by the Queensland. The Amalgamated States National Institutes of Health (NIH) is cooperating with Modern to engender associate ribonucleic acid vaccinum matching a spike of the coronavirus surface, and intends to begin human tribulations by could 2020. Invivo prescription drugs is developing a DNA-predicated vaccination and collaborating with a Chinese firm, hoping to perform human tribulations within the summer of 2020 [91] In Australia, the University of Queensland is investigation the potential of a molecular clamp vaccinum that will genetically modify infective agent proteins so as to stimulate associate reaction. In Canada, the International vaccinum Centre (VIDOInterVac), University of Saskatchewan, square measure engaged on a vaccinum, aiming to begin animal testing in March 2020 and human testing in 2021 [92]. In Gregorian calendar month 2020, Janssen Pharmaceutical corporations commenced work on developing a vaccinum, utilizing an equivalent technologies wont to build its experimental viral haemorrhagic fever vaccinum [93] within the following month, the U.S. Department of Health and Human Accommodations' medicine Advanced analysis and Development dominance (BARDA) publicized that it'd collaborate with Janssen and, later, Sanofi biologist (the vaccinum division of Sanofi) to develop a vaccinum [94]. Sanofi has overtime worked on a vaccinum for respiratory illness and it verbally expressed to expect to own a vaccinum candidate inside six months that would be used to check in individuals inside a year to eighteen months.

\section{Antiviral}

- No drug has however been approved to treat coronavirus infections in humans. analysis into potential treatments for the illness was initiated in Gregorian calendar month 2020, and a number of other antiviral medicine square measure already in clinical tribulations [95] Albeit completely early medicine could take till 2021 to develop, many of the medicine being tested square measure already approved for different antiviral denotements, or square measure already in advanced testing.

- Antiviral being tested embrace ant malarial drug, darunavir, galidesivir, antiviral agent beta. The lopinavir/ritonavir conglutination, professional 140; REGN3048-3051 (Regeneron), an accumulation of 2 neutralizing organism antibodies the ribonucleic acid enzyme substance remdesivir and triazavirin.

- Arbidol and Darunavir were planned by the National Health Commission.

- One multicentre trial has shown antimalarial drug to be efficacious and safe in COVID-19 associated respiratory illness. The drug is in addition being according to be enclosed in tips for the preclusion, Diagnosis, and Treatment of respiratory illness Caused by COVID-19 issued by the National Health Commission of the People's Republic of China for treatment of COVID-19 infection in additional vastly large populations within the future.

\section{Conclusion}

The present review illustrates various causative agents responsible for the corona virus infection. Presently there is no any treatment and drug is available to treat corona virus infection disease cause due to this, so we people believe into the prevention is better than cure concept. Multidrug drug treatment of antiviral and antimalarial drugs will be helpful to treat this disease as per the till date. Corona is most communicable disease of today's date, That's why we will follow the guidelines given by the WHO, time to time try to avoid the contact with the infection ns person avoid to shake hands and make habit to say NAMASTE to everyone.

Authorship Contributions: Concept - R. Bodhe , V. Jadhao , H. Mahajan ; Design - R. Bodhe , V.Jadhao .; Supervision H.Mahajan, K. Patil ; Data collection\&/or processing - V. Jadhav , N. Kale ; Analysis and/or interpretation -R. Bodhe, N. Kale, V.Jadhao, K. Patil , V. Jadhav.; Literature search - R. Bodhe , V.Jadhao, N. Kale , , K. Patil , V. Jadhav.; Writing -R. Bodhe , V.Jadhao.; Critical review - K. Patil, H. Mahajan.

\section{References}

1. Wertheim JO, Chu DK, Peiris JS, Pond SL, Poon LL. A case for the ancient origin of corona viruses. Journal of Virology. 2013 Jun 15; 87(12):7039-45. International Committee on Taxonomy of Viruses. Elsevier, Oxford. pp. 806-828.

2. Geller C, Varbanov M, Duval RE. "Human corona viruses: insights into environmental resistance and its influence on the development of new antiseptic strategies". Viruses. 2012; 4(11):3044-3066.

3. Li F, Li W, Farzan M, Harrison SC. "Structure of SARS coronavirus spike receptor-binding domain complexes with receptor". Science. 2005; 309(5742):1864-1868. Bibcode: 2005Sci...309.1864L. Doi: 10.1126/science. 1116480 PMID 16166518.

4. Sexton NR, Smith EC, Blanc H, Vignuzzi M, Peersen OB, Denison MR. "Homology-Based Identification of a Mutation in the Coronavirus RNA-Dependent RNA Polymerase That Confers Resistance to Multiple Mutagens". Journal of Virology. 2016; 90(16):7415-7428. Doi: 10.1128/JVI.00080-16. PMC 4984655 PMID 27279608.

5. Fehr AR, Perlman S. "Corona viruses: an overview of their replication and pathogenesis". Corona viruses. Methods in Molecular Biology. 2015; 1282:1-23. Doi: 10.1007/978-1-49392438-7_1. ISBN 978-1-4939-2437-0. PMC 4369385. PMID 25720466.

6. Coronavirus disease named Covid-19". BBC News Online. 11 February 2020. Archived from the original on 15 February 2020. Retrieved 15 February 2020.

7. World Health Organization (2020). Surveillance case definitions for human infection with novel coronavirus (nCoV): interim guidance v1, January 2020 (Report). World Health Organization. hdl: 10665/330376. WHO/2019-nCoV/Surveillance/v2020.1

8. "Healthcare Professionals: Frequently Asked Questions and Answers". U.S. Centers for Disease Control and Prevention (CDC). 11 February 2020. Archived from the original on 14 February 2020. Retrieved 15 February 2020

9. People's Republic of China: Chinese canter for Disease Control and Prevention. Archived from the original on 6 February 2020. Retrieved 9 January 2020.

10. "New-type coronavirus causes pneumonia in Wuhan: expert". People's Republic of China. Xinhua. Archived from the original on 9 January 2020. Retrieved 9 January 2020.

11. "CoV2020". GISAID EpifluDB. Archived from the original on 12 January 2020. Retrieved 12 January 2020.

12. Chan JF, Yuan S, Kok KH, et al. (January 2020). "A familial cluster of pneumonia associated with the 2019 novel coronavirus indicating person-to-person transmission: a study of a family cluster". Lancet. 395 (10223): 514-523. doi:10.1016/S01406736(20)30154-9. PMID 31986261. 
13. Steenhuysen J, Kelland K (24 January 2020). "With Wuhan virus genetic code in hand, scientists begin work on a vaccine". Reuters. Archi

14. Zhou P, Yang XL, Wang XG, et al. (February 2020). "A pneumonia outbreak associated with a new coronavirus of probable bat origin". Nature: 1-4. doi:10.1038/s41586-020-2012-7. PMID 32015507.

15. Perlman S (January 2020). "Another Decade, Another Coronavirus". New England Journal of Medicine. doi:10.1056/NEJMe2001126. PMID 31978944.

16. Benvenuto D, Giovanetti M, Ciccozzi A, et al. (January 2020). "The 2019-new coronavirus epidemic: Evidence for virus evolution". Journal of Medical Virology. doi:10.1002/jmv.25688. PMID 31994738.

17. World Health Organization (2020). Novel Coronavirus (2019nCoV): situation report, 22 (Report). World Health Organization. hdl:10665/330991.

18. Shield, Charli ( 7 February 2020). "Coronavirus: From bats to pangolins, how do viruses reach us?".Deutsche Welle. Retrieved 15 February 2020.

19. Wee S, McNeil Jr DG, Hernández JC (30 January 2020). "W.H.O. Declares Global Emergency as Wuhan Coronavirus Spreads". The New York Times. Archived from the original on 30 January 2020. Retrieved 30 January 2020.

20. Huang P (22 January 2020). "How Does Wuhan Coronavirus Compare with MERS, SARS and the Common Cold?".NPR. Archived from the original on 2 February 2020. Retrieved 3 February 2020.

21. Fox D (2020). "What you need to know about the Wuhan coronavirus". Nature. Doi:10.1038/d41586-020-00209-y. ISSN 0028-0836.

22. "Symptoms of Novel Coronavirus (2019-nCoV) | CDC". U.S Centers for Disease Control and Prevention (CDC). 10 February 2020. Retrieved 11 February 2020.

23. "2019 Novel Coronavirus (2019-nCoV)". Canters for Disease Control and Prevention. 11 February 2020.

24. "Prevention and Treatment". Centers for Disease Control and Prevention (CDC). 9 August 2019. Archived from the original on 15 December 2019. Retrieved 21 January 2020.

25. "Prevention and Treatment". Centers for Disease Control and Prevention (CDC). 9 August 2019. Archived from the original on 15 December 2019. Retrieved 21 January 2020.

26. "Updates on Wuhan Coronavirus (2019-nCoV) Local Situation". moh.gov.sg. Retrieved 1 February 2020.

27. "The Deadliest Epidemics Of The 21st Century So Far". World Atlas. Retrieved 20 February 2020.

28. "Coronavirus Global COVID-19 Cases". Gisanddata.maps.arcgis.com. Johns Hopkins CSSE. Retrieved 17 February 2020.

29. "Coronavirus Update (Live):69,268 Cases and 1,665 Deaths from the Wuhan China Virus Outbreak - Worldometer". www.worldometers.info. Retrieved 8 February 2020.

30. "The Epidemiological Characteristics of an Outbreak of 2019 Novel Coronavirus (COVID-19), China 2020"(PDF). CCDC Weekly. 2. 19 February 2020.

31. Imai, Natsuko; Dorigatti, Ilaria; Cori, Anne; Donnelly, Christl; Riley, Steven; Ferguson, Neil M (21 January 2020). "Estimating the potential total number of novel Coronavirus cases in Wuhan City, China (Report 2"(PDF). Imperial College London. Archived(PDF) from the original on 24 January 2020.

32. "HKUMed WHO Collaborating Centre for Infectious Disease Epidemiology and Control releases real-time nowcast on the likely extent of the Wuhan coronavirus outbreak, domestic and international spread with the forecast for chunyun". HKUMed School of Public Health. Archived from the original on 25 January 2020. Retrieved 23 January 2020.

33. "Tracking coronavirus: Map, data and timeline". BNO News. 10 February 2020. Archived from the original on 28 January 2020.

34. World Health Organization (2020). Novel Coronavirus (2019 nCoV): situation report, 13(PDF) (Report). World Health Organization. hdl:10665/330778.

35. mvichian-Clausen, Austa (30 January 2020). "The coronavirus is causing an outbreak in America-of anti-Asian racism". The Hill. Archived from the original on 1 February 2020.

36. "Wuhan lockdown 'unprecedented', shows commitment to contain virus: WHO representative in China". Reuters. 23 January 2020. Archived from the original on 24 January 2020.
37. Griffiths, James; Woodyatt, Amy. "Wuhan coronavirus: Thousands of cases confirmed as China goes into emergency mode". CNN. Archived from the original on 28 January 2020. Retrieved 1 February 2020.

38. "Zhejiang province next to Shanghai adopts draconian quarantine measures". South China Morning Post. 6 February 2020. Archived from the original on 6 February 2020. Retrieved 8 February 2020

39. "2019-nCoV information for Travelers". U.S. Centers for Disease Control and Prevention (CDC). 3 February 2020. Archived from the original on 30 January 2020. Retrieved 6 February 2020.

40. Deerwester, Jayme; Gilbertson, Dawn. "Coronavirus: US says 'do not travel' to Wuhan, China, as airlines issue waivers, add safeguards". USA Today. Archived from the original on 27 January 2020. Retrieved 26 January 2020.

41. "Coronavirus Update: Masks And Temperature Checks In Hong Kong". Nevada Public Radio. Retrieved 26 January 2020.

42. Warren, Tom (12 February 2020). "The world's biggest phone show has been canceled due to coronavirus concerns". The Verge. Retrieved 14 February 2020.

43. Kuo, Lily (11 February 2020). "China fires two senior Hubei officials over coronavirus outbreak". The Guardian. Retrieved 18 February 2020.

44. Young, Evan (31 January 2020). "'This is racism': ChineseAustralians say they've faced increased hostility since the coronavirus outbreak began". Special Broadcasting Service.

45. Iqbal, Nosheen (1 February 2020). "Coronavirus fears fuel racism and hostility, say British-Chinese". The Observer ISSN 0029-7712. Archived from the original on 3 February 2020.

46. "Coronavirus fears trigger anti-China sentiment across the globe". Global News. Archived from the original on 3 February 2020.

47. Yeung, Jessie. "As the coronavirus spreads, fear is fueling racism and xenophobia". CNN. Archived from the original on 3 February 2020. Retrieved 4 February 2020.

48. Capatides, Christina (14 February 2020). "Bullies attack Asian American teen at school, accusing him of having coronavirus". CBS News.

49. World Health Organization (11 February 2020). Novel Coronavirus (2019-nCoV): situation report, 22(PDF) (Report). World Health Organization,

50. Gorbalenya, Alexander E. (11 February 2020). "Severe acute respiratory syndrome-related coronavirus - The species and its viruses, a statement of the Coronavirus Study Group". bioRxiv: 2020.02.07.937862. doi:10.1101/2020.02.07.937862.

51. "Coronavirus disease named Covid-19". BBC News. 11 February 2020. Archived from the original on 11 February 2020.

52. Hui DS, I Azhar E, Madani TA, Ntoumi F, Kock R, Dar O, Ippolito G, Mchugh TD, Memish ZA, Drosten C, Zumla A, Petersen E. The continuing 2019-nCoV epidemic threat of novel coronaviruses to global health - The latest 2019 novel coronavirus outbreak in Wuhan, China. Int J Infect Dis. 2020 Jan 14;91:264-266.

53. "Q\&A on coronaviruses". World Health Organization (WHO). Archived from the original on 20 January 2020. Retrieved 27 January 2020.

54. 2019 Novel Coronavirus (2019-nCoV)". Centers for Disease Control and Prevention. 11 February 2020. Retrieved 18 February 2020

55. "Symptoms of Novel Coronavirus (2019-nCoV) | CDC". www.cdc.gov. 10 February 2020. Archived from the original on 30 January 2020. Retrieved 11 February 2020.

56. "MOH | Updates on 2019 Novel Coronavirus (2019-nCoV) Local Situation". www.moh.gov.sg. Retrieved 11 February 2020.

57. Wang D, Hu B, Hu C, Zhu F, Liu X, Zhang J, Wang B, Xiang H, Cheng Z, Xiong Y, Zhao Y, Li Y, Wang X, Peng Z (February 2020). "Clinical Characteristics of 138 Hospitalized Patients With 2019 Novel Coronavirus-Infected Pneumonia in Wuhan, China". JAMA. doi:10.1001/jama.2020.1585. PMID 32031570.

58. "Areas with presumed ongoing community transmission of 2019-nCoV". European Centre for Disease Prevention and Control. Archived from the original on 19 February 2020.

59. "Tracking coronavirus: Map, data and timeline". BNO News. 10 February 2020. Archived from the original on 28 January 2020.

60. CDC (11 February 2020). "2019 Novel Coronavirus (2019$\mathrm{nCoV}) "$. Centers for Disease Control and Prevention.

61. "Advice for public". www.who.int. Retrieved 15 February 2020.

62. Statement on the second meeting of the International Health Regulations (2005) Emergency Committee regarding the 
outbreak of novel coronavirus (2019-nCoV)". www.who.int. Archived from the original on 31 January 2020.

63. "Areas with presumed ongoing community transmission of 2019-nCoV". European Centre for Disease Prevention and Control. Archived from the original on 19 February 2020.

64. Li W, Shi Z, Yu M, et al. "Bats are natural reservoirs of SARS-like coronaviruses". Science. 2005; 310(5748):6769.Bibcode:2005Sci...310..676L.

65. ${ }^{\wedge}$ "Scientists prove SARS-civet cat link". China Daily. 23 November 2006. Archived from the original on 14 June 2011.

66. WHO. WHO Statement Regarding Cluster of Pneumonia Cases in Wuhan, China Geneva2020 [Cited 14 February 2020]. Available from: https://www.who.int/china/news/detail/09-01-2020who-statement-regarding-cluster-of-pneumoniacases-inwuhan-china.

67. Zhu N, Zhang D, Wang W, Li X, Yang B, Song J, et al. A Novel Coronavirus from Patients with Pneumonia in China, 2019. New England Journal of Medicine. 2020.

68. Zhou PX-L, Y; Xian-Guang, W; et al. A pneumonia outbreak associated with a new coronavirus of probable bat origin. Nature. 2 Feb 2020

69. Wang D, Hu B, Hu C, Zhu F, Liu X, Zhang J, et al. Clinical Characteristics of 138 Hospitalized Patients With 2019 Novel Coronavirus-Infected Pneumonia in Wuhan, China. JAMA. 7 Feb 2020.

70. Kim JY, Choe PG, Oh Y, Oh KJ, Kim J, Park SJ, et al. The First Case of 2019 Novel Coronavirus Pneumonia Imported into Korea from Wuhan, China: Implication for Infection Prevention and Control Measures. J Korean Med Sci. 2020 Feb 10;35(5):e61.

71. Huang C, Wang Y, Li X, Ren L, Zhao J, Hu Y, et al. Clinical features of patients infected with 2019 novel coronavirus in Wuhan, China. The Lancet. 2020 January 24.

72. Wei-jie G, Zheng-yi N; Yu H, Wen-Hua L, Chun-Quan O, Jian-Xing $\mathrm{H}$, et al. Clinical characteristics of 2019 novel coronavirus infection in China. 2020. Available from: https://www.medrxiv.org/content/10.1101/2020.02.06.20020 974.

73. Holshue ML, DeBolt C, Lindquist S, Lofy KH, Wiesman J, Bruce H, et al. First Case of 2019 Novel Coronavirus in the United States. New England Journal of Medicine. 2020.

74. Chan JF, Yuan S, Kok KH, et al. (January 2020). "A familial cluster of pneumonia associated with the 2019 novel coronavirus indicating person-to-person transmission: a study of a family cluster". Lancet. 395 (10223): 514-523. doi:10.1016/S01406736(20)30154-9. PMID 31986261.

75. "How does coronavirus spread?".NBC News. Archived from the original on 28 January 2020. Retrieved 29 January 2020.

76. "Transmission of Novel Coronavirus (2019-nCoV)". U.S. Centers for Disease Control and Prevention (CDC). 27 January 2020 Archived from the original on 28 January 2020. Retrieved 29 January 2020.

77. Holshue ML, DeBolt C, Lindquist S, et al. (January 2020). "First Case of 2019 Novel Coronavirus in the United States". New England Journal of Medicine. doi:10.1056/NEJMoa2001191. PMID 32004427.

78. Kupferschmidt K (February 2020). "Study claiming new coronavirus can be transmitted by people without symptoms was flawed". Science. doi:10.1126/science.abb1524.

79. Zhu N, Zhang D, Wang W, et al. (January 2020). "A Novel Coronavirus from Patients with Pneumonia in China, 2019". New England Journal of Medicine. doi:10.1056/NEJMoa2001017. PMID 31978945.

80. Huang, Chaolin; Wang, Yeming; Li, Xingwang; Ren, Lili; Zhao, Jianping; Hu, Yi; Zhang, Li; Fan, Guohui; Xu, Jiuyang; Gu, Xiaoying; Cheng, Zhenshun (24 January 2020). "Clinical features of patients infected with 2019 novel coronavirus in Wuhan, China". Lancet. 395 (10223): 497-506. doi:10.1016/S01406736(20)30183-5. ISSN 0140-6736. PMID 31986264

81. Gorbalenya, Alexander E. (11 February 2020). "Severe acute respiratory syndrome-related coronavirus - The species and its viruses, a statement of the Coronavirus Study Group". bioRxiv: 2020.02.07.937862. doi:10.1101/2020.02.07.937862. Archived from the original on 11 February 2020. Retrieved 11 February 2020.

82. "Shanghai officials reveal novel coronavirus transmission modes - Chinadaily.com.cn". www.chinadaily.com.cn.

83. "The Epidemiological Characteristics of an Outbreak of 2019 Novel Coronavirus Diseases (COVID-19) - China, 2020"(PDF) China CDC Weekly. 2. 20 February 2020 - via unpublished master.

84. Jin, Ying-Hui; Cai, Lin; Cheng, Zhen-Shun; Cheng, Hong; Deng, Tong; Fan, Yi-Pin; Fang, Cheng; Huang, Di; Huang, Lu-Qi; Huang, Qiao; Han, Yong (6 February 2020). "A rapid advice guideline for the diagnosis and treatment of 2019 novel coronavirus (2019$\mathrm{nCoV}$ ) infected pneumonia (standard version)". Military Medical Research. 7 (1): 4. doi:10.1186/s40779-020-0233-6. ISSN 20549369. PMID 32029004.

85. 2019 Novel Coronavirus (2019-nCoV) Situation Summary". Centers for Disease Control and Prevention. 30 January 2020. Archived from the original on 26 January 2020.

86. CDC (5 February 2020). "CDC Tests for 2019-nCoV". Centers for Disease Control and Prevention. Retrieved 12 February 2020.

87. "Chinese scientists race to develop vaccine as coronavirus death toll jumps". South China Morning Post. 26 January 2020. Archived from the original on 26 January 2020. Retrieved 28 January 2020.

88. MazumdarA T (30 January 2020). "Coronavirus: Scientists race to develop a vaccine". BBC News Online. Archived from the original on 30 January 2020. Retrieved 3 February 2020.

89. "Saskatchewan lab joins global effort to develop coronavirus vaccine". Canadian Broadcasting Corporation. 24 January 2020. Archived from the original on 25 January 2020. Retrieved 25 January 2020.

90. Mishra M (29 January 2020). "Johnson \& Johnson working on vaccine for deadly coronavirus". Reuters. Archived from the original on 29 January 2020. Retrieved 19 February 2020.

91. "HHS Engages Sanofi's Recombinant Technology for 2019 Novel Coronavirus Vaccine". U.S. Department of Health \& Human Services (HHS) (Press release). 14 February 2020. Retrieved 19 February 2020.

92. Praveen Duddu. Coronavirus outbreak: Vaccines/drugs in the pipeline for Covid-19. Clinicaltrialsarena.com 19 February 2020.

93. Are cocktail therapies for flu and HIV the magic cure for coronavirus?".South China Morning Post. 4 February 2020 Retrieved 22 February 2020.

\section{External links:}

International health authorities:

- WHO: Coronavirus disease (COVID-19) by World Health Organization

- CDC: Coronavirus Disease 2019 (COVID-19) by Centres for Disease Control and Prevention

- ECDC: COVID-19 by European Centre for Disease Prevention and Control

- $\quad$ NHS: Coronavirus (COVID-19) by NHS

Data and maps:

- $\quad$ Coronavirus disease (COVID-2019) situation reports by World Health Organization (official numbers of confirmed cases by country)

- 2019 Novel Coronavirus Map by Medgic (using official Chinese sources)

- Worldwide Coronavirus Map, confirmed Cases - Map the route paths of coronavirus confirmed cases.

- Coronavirus COVID-19 Global Cases and historical data by Johns Hopkins University

- COVID-19 Epidemiologic and genetic data from the Wolfram data repository.

- 2019-nCoV Data Portal by Virus Pathogen Resource

- CoronatrackerA - Coronavirus news aggregator and tracking portal 